\title{
The Application Research on Safety performance Evaluation of Portal Crane based on Reliability Evaluation and risk Assessment
}

\author{
Li Qin ${ }^{1, *}$, Bin Zhang ${ }^{2}$, Li-xinRen ${ }^{3}$, Zheng-qiu Huang ${ }^{3}$ \\ ${ }^{1}$ Shanghai Pudong New Area Special Equipment Inspection Institute, Shanghai, 201210 \\ ${ }^{2}$ Shanghai Fengxian District Special Equipment Inspection Institute, Shanghai 201406 \\ ${ }^{3}$ Shanghai Institute of Special Equipment Inspection and Technical Research, Shanghai 200062
}

\begin{abstract}
With the continuous development of modern industry in our country, the use of cranes is becoming more and more common, but the unsafe incidents of cranes occur from time to time, which makes the risk assessment of cranes more and more important. Crane risk assessment has become an important part of crane risk management. In order to further promote the development of crane risk management, this paper tests the feasibility and effectiveness of this method through the study of fuzzy safety evaluation method and the direct application of this method to the risk assessment of portal crane.
\end{abstract}

\section{Introduction}

With the development of social productive forces and the continuous development of modernization, cranes have become an important equipment for daily industrial construction. In recent years, the production and marketing of crane equipment in our country has maintained a stable growth rate, its utilization rate in various industries has been increasing, the utilization rate of cranes has been increasing, and the number of different types of cranes has been increasing, which is of great significance to the development of modern industry in our country, but there are increasingly significant safety problems.

At present, crane accidents occur frequently in our country, and the present situation of crane safety is more serious. It is urgent to improve the level of crane risk assessment and effectively prevent crane accidents. Once the safety assessment system cannot keep up with the speed of crane use, the risk of crane will intensify, and sudden accidents will seriously affect the use of cranes and limit the development speed of modern industry in our country. Based on this, this paper studies the crane risk assessment method.

\section{Overview of security assessment}

Safety assessment is also known as risk assessment, in fact, it is to evaluate and analyze the risks caused or potential in the working process of a specific system or equipment, to carry out qualitative or quantitative analysis with the corresponding parameters and indicators, and then to obtain a quantitative value or probability value, and to analyze the risk accidents that have occurred, it is to use certain evaluation principles or analysis methods to analyze. Finally, according to the size of the quantitative value, the preventive or protective countermeasures are taken. The safety assessment of crane is based on the operation technology of crane equipment, using fuzzy safety evaluation method, accident tree analysis method, analytic hierarchy process (AHP) and other methods to analyze the accidents or potential risks that have occurred, and then draw the corresponding conclusions, which provides the basis for the risk prevention of cranes ${ }^{[1]}$.

\subsection{Captions/numbering}

Fuzzy safety evaluation method is a kind of commonly used evaluation method, which mainly uses different evaluation indexes to evaluate many aspects of the evaluation object, sets the specific evaluation index in the evaluation process, and determines the corresponding weight coefficient, and then carries on the dimensionless processing to the evaluation description, forms the data evaluation information, uses the corresponding calculation formula to test the evaluation value, determines the final evaluation state, then carries on the dimensionless processing to the evaluation description, forms the data evaluation information, uses the corresponding calculation formula, carries on the test to the evaluation value, determines the final evaluation state. Form the final evaluation report ${ }^{[2]}$.

The fuzzy safety evaluation method calculates the specific data according to the fixed calculation formula, and reflects the final evaluation state according to the calculation results, and the evaluation results can quickly and accurately obtain the safety state of the evaluation

$\overline{* \text { Corresponding author: tongyt } @ \text { ssei.cn }}$ 
object according to the final calculated average value. The scope of its application should meet two conditions, one is that the applicable object needs to have the running state, and the relevant indexes of its running process can be dimensionless to form the calculated data; the other is that the evaluation object should have the original data and constant parameters, which can be used to confirm the evaluation index.

\subsection{Evaluation steps of fuzzy safety evaluation method}

\subsubsection{Deterministic factor set}

Set up the factor set (U). According to the number of evaluation indicators, set $\left(\mathrm{u}_{1}, \mathrm{u} 2 \ldots \mathrm{u}_{\mathrm{n}}\right), \mathrm{n}=1,2,3 \ldots \mathrm{n}$. In order to make clear the allocation of the weight value of the evaluation index or the corresponding evaluation value allocation, according to the attributes of the evaluation object, the evaluation index is subdivided and hierarchical processing.

\subsubsection{Determine the set of comments}

According to the factor set, the corresponding evaluation set $(V)$ is established, set $\left(v_{1}, v_{2} \ldots v_{n}\right), n=1,2,3 \ldots n$. that is, the set of all the evaluation results made by the experts on the evaluated factors. The corresponding fuzzy subset is provided for the fuzzy judgment matrix.

\subsubsection{Determine the weight vector}

In one case, the weight vector is calculated by the single factor evaluation value and the corresponding weight assignment, and $\mathrm{w}=(\mathrm{w} 1, \mathrm{w} 2, \mathrm{w} 3 \ldots \ldots \mathrm{wn})$, and in the other case, when the weight vector is not known, the corresponding $A=(a 1, a 2 \ldots$ an) is set as the weight fuzzy vector, where ai represents the weight of the i-th factor.

\subsubsection{Establishing fuzzy relation matrix}

Based on the single factor evaluation, in order to further determine the membership relationship between the selected evaluation set and the factor set, judge the reasonable relationship between the factor set and the evaluation set, and establish the corresponding fuzzy relation matrix. $\mathrm{R}$ ( or $\mathrm{r}$ ) is used to represent the membership value of the evaluation fuzzy relational matrix ${ }^{[3]}$. $R_{i j}$ is used to represent the membership degree of an evaluated object to the hierarchical fuzzy subset $v_{j}$ from the perspective of factor $u_{i}$. Where $r_{i}=\left(r_{i 1}, r_{i 2} \ldots r_{i n}\right)$. Normalization: $\sum \mathrm{rij}=1^{[3]}$.

\subsubsection{Finding the value of single Factor Evaluation Matrix}

After the fuzzy relation matrix between factor set $U$ and evaluation set $\mathrm{V}$ is established, the membership relationship between the two groups can be determined, and the corresponding evaluation grade can be set by using experts directly or other professionals to give the evaluation grade, and then the item scores of different evaluation grades can be counted, and the value of single factor evaluation matrix can be obtained according to the calculation formula. The formula (1) is as follows ${ }^{[4]}$.

$$
r_{i j}=\left\{\begin{array}{l}
1,(i=j) \\
1-c \sum_{k-1}\left|x_{i k}-x_{j k}\right|,(i \neq j)
\end{array}\right.
$$

$\mathrm{c}$ is the correction factor.

\subsubsection{Determine the results of fuzzy comprehensive evaluation}

The final fuzzy comprehensive evaluation result set $\mathrm{B}$ is obtained by using fuzzy synthesis vector A and fuzzy relation matrix $\mathrm{R}$. The model of fuzzy comprehensive evaluation result set $\mathrm{B}$ is as follows:

$$
B=A \bullet R=\left(a_{1}, a_{2}, \cdots, a_{m}\right)\left(\begin{array}{llll}
r_{11} & r_{12} & \cdots & r_{13} \\
r_{21} & r_{22} & \cdots & r_{23} \\
\vdots & \vdots & \ddots & \vdots \\
r_{m 1} & r_{m 2} & \cdots & r_{m n}
\end{array}\right)=\left(b_{1}, b_{2}, \cdots, b_{n}\right)
$$

\subsection{Safety assessment index system}

On the overall level of crane operation, the safety evaluation index includes the equipment failure of crane, improper operation of personnel and related management system. On the premise of not distinguishing different types of cranes, the commonness of all types of cranes is set, and the descriptive index is suitable for the safety assessment of all cranes. Among the descriptive indexes, the second index is fracture, deformation, corrosion, damage, inspection and maintenance, and the three indexes involve the fracture, deformation corrosion and maintenance of specific crane parts (accessories), such as the deformation of boom, pull rod and wire rope. The degree of maintenance (overhaul, minor repair) ${ }^{[5]}$. As shown in table 1 .

\begin{tabular}{|c|c|c|c|}
\hline Index & Indicators 1 & Indicators 2 & Indicators 3 \\
\hline $\begin{array}{l}\text { First-level } \\
\text { indicators }\end{array}$ & $\begin{array}{c}\text { Crane } \\
\text { equipment } \\
\text { status }\end{array}$ & $\begin{array}{l}\text { Personnel } \\
\text { operation }\end{array}$ & $\begin{array}{l}\text { Management } \\
\text { System }\end{array}$ \\
\hline $\begin{array}{l}\text { Secondary } \\
\text { indicators }\end{array}$ & $\begin{array}{l}\text { Strength, } \\
\text { stiffness, } \\
\text { corrosion, } \\
\text { deformation } \\
\text {, cracks, } \\
\text { repair }\end{array}$ & $\begin{array}{c}\text { Change } \\
\text { operation } \\
\text { action, } \\
\text { operation } \\
\text { time, } \\
\text { operation } \\
\text { status, } \\
\text { situation } \\
\text { handling (on- } \\
\text { site judgment, } \\
\text { lifting } \\
\text { operation) }\end{array}$ & $\begin{array}{c}\text { Technical } \\
\text { management } \\
\text { system, safety } \\
\text { management } \\
\text { system, } \\
\text { equipment } \\
\text { management } \\
\text { system, site } \\
\text { management } \\
\text { system, } \\
\text { personnel } \\
\text { management } \\
\text { system }\end{array}$ \\
\hline
\end{tabular}

Table 1 Safety index of crane. 


\subsection{Classification of fuzzy safety evaluation results}

\subsubsection{Classification of crane equipment evaluation results}

Set the corresponding V, used to describe the safety state of the metal structure of crane equipment, and carry on the classification. Set v1 $(-\infty, 0)$, the structure or the whole crane equipment is completely scrapped, cannot be used and repaired. v2 $[0,0.2)$, the crane cannot be put into operation, need to carry out a long period of largescale repair. v3 $[0.2,0.4)$, the crane has a serious risk of operation failure. According to the weight value of different indexes, the specific objects that need to be repaired greatly are analyzed, and the corresponding repair scheme needs to be worked out, and if necessary, the operation needs to be stopped. v4 $[0.4,0.6)$, the structure has hidden trouble, so it is necessary to strengthen regular inspection and repair according to different indexes. v5 $[0.6,0.8)$, the structure is in normal operation state, the risk assessment of crane is low, but there is a slight damage, so it is necessary to strengthen the inspection. v6 $[0.8,1)$, the structure runs well and the overall safety index is high.

\subsubsection{Classification of Evaluation results of Crane Operation Indexes}

The corresponding $\mathrm{V}$ is set to describe the safety state of the crane operation, and the classification is carried out. Set v1 $(-\infty, 0)$, the human operation is completely wrong, there is a major risk fault. v2 $[0,0.2)$, there is a major error in human operation, resulting in a high risk accident. v3 $[0.2,0.4)$, there is a risk in crane operation, which requires technical safety re-guidance. $v 4[0.4,0.6)$, there are small errors in human operation, and the operation details need to be corrected in a timely manner. v5 $[0.6,0.8)$, there is no mistake in human operation, and the risk assessment of crane is low. v6 $[0.8,1)$, the manmade operation is better, and the overall safety index is higher.

\subsubsection{Classification of Evaluation results of Crane Management system Indexes}

Set up the corresponding V, used to describe the safety state of the crane management system, and carry on the classification. When v1 $(-\infty, 0)$ is set up, there are significant deficiencies and risks in the management system. v2 [0, 0.2), lack of important elements of the management system, resulting in high-risk accidents. v3 $[0.2,0.4)$, the management system is not perfect enough and needs to be further improved and implemented. v4 $[0.4,0.6)$, the details of the management system need to be supplemented in a timely manner. v5 $[0.6,0.8)$, the management system is basically perfect, and the risk assessment of cranes is low. v6 $[0.8,1)$, the management system is perfect, and the overall safety index is high.

\subsubsection{Classification of Evaluation results from three aspects}

When $\mathrm{v} 1(-\infty, 0)$ is set, there is a significant risk to the crane. v2 $[0,0.2)$, crane risk index is high. v3 $[0.2,0.4)$, cranes have a moderate risk. $\mathrm{v} 4[0.4,0.6)$, the risk of crane is small. v5 $[0.6,0.8)$, cranes have little risk. v6 $[0.8,1)$, the safety index of crane is high.

\section{Application of fuzzy safety evaluation method in enterprises}

In an enterprise in Shanghai, the fuzzy safety evaluation method is used to evaluate the safety of an in-service door crane. According to the daily inspection table of the crane, it can be seen that its equipment is relatively new and there is no major failure report in the process of use. At the same time, its operators implement the double assessment system inside and outside the enterprise, the operation technology of the operator is better, and the average length of service of the operator reaches 7 years. The relevant management system documents and regulations within the enterprise are consulted, and the relevant management system as a whole is set up more clearly. Based on this, the expert system is used to evaluate the crane safety system of the enterprise, and the basic information of the expert is shown in Table 2 .

Table 2 Expert Basic Information Form.

\begin{tabular}{|c|c|c|c|c|}
\hline Name & Age & Company & Title & Profession \\
\hline $\begin{array}{c}\text { Expert } \\
\text { one }\end{array}$ & 58 & $\begin{array}{c}\text { Safety } \\
\text { Science } \\
\text { Research } \\
\text { Institute }\end{array}$ & $\begin{array}{c}\text { Professor of } \\
\text { engineering }\end{array}$ & $\begin{array}{c}\text { Special } \\
\text { equipment }\end{array}$ \\
\hline $\begin{array}{c}\text { Expert } \\
\text { two }\end{array}$ & 59 & $\begin{array}{c}\text { Special } \\
\text { equipment } \\
\text { research } \\
\text { institute }\end{array}$ & $\begin{array}{c}\text { Professor of } \\
\text { engineering }\end{array}$ & $\begin{array}{c}\text { Special } \\
\text { equipment }\end{array}$ \\
\hline $\begin{array}{c}\text { Expert } \\
\text { three }\end{array}$ & 55 & $\begin{array}{c}\text { Special } \\
\text { equipment } \\
\text { research } \\
\text { institute }\end{array}$ & $\begin{array}{c}\text { Professor of } \\
\text { engineering }\end{array}$ & $\begin{array}{c}\text { Special } \\
\text { equipment }\end{array}$ \\
\hline
\end{tabular}

On the basis of the first-level index, the expert score is estimated, and the scoring probability of the three experts is set as shown in Table 3. The probability that the average score of the equipment state index is $\mathrm{v} 6$ is 0.867 , the probability of $v 5$ is 0.133 , and the other scoring probabilities are all 0 . The probability of the average score of the expert to the management system index is v 5 is 0.05 , the probability of $\mathrm{v} 4$ is 0.1 , the probability of $\mathrm{v} 3$ is 0.085 , and the other scoring probabilities are all 0 . The probability of experts scoring the human operation index as $\mathrm{v} 6$ is 0.95 , the probability of $v 5$ is 0.05 , and the probability of other scores is 0 . 
Table 3 Expert scoring of crane evaluation value estimation evaluation result probability

\begin{tabular}{|l|l|l|l|l|l|l|}
\hline & v1 & v2 & v3 & v4 & v5 & v6 \\
\hline Indicator: Equipment status (0.4) \\
\hline Expert 1 & 0 & 0 & 0 & 0.15 & 0.85 \\
\hline Expert 2 & 0 & 0 & 0 & 0.15 & 0.85 \\
\hline Expert 3 & 0 & 0 & 0 & 0.1 & 0.9 \\
\hline $\begin{array}{l}\text { average } \\
\text { value }\end{array}$ & 0 & 0 & 0 & 0.133 & 0.867 \\
\hline Indicator: Management System (0.3) \\
\hline Expert 1 & 0 & 0.85 & 0.1 & 0.05 & 0 \\
\hline Expert 2 & 0 & 0.8 & 0.1 & 0.1 & 0 \\
\hline Expert 3 & 0 & 0.9 & 0.1 & 0 & 0 \\
\hline $\begin{array}{l}\text { average } \\
\text { value }\end{array}$ & 0 & 0.85 & 0.1 & 0.05 & 0 \\
\hline Indicator: Human operation $(0.3)$ & \\
\hline Expert 1 & 0 & 0 & 0 & 0.05 & 0.95 \\
\hline Expert 2 & 0 & 0 & 0 & 0.05 & 0.95 \\
\hline Expert 3 & 0 & 0 & 0 & 0.05 & 0.95 \\
\hline $\begin{array}{l}\text { average } \\
\text { value }\end{array}$ & 0 & 0 & 0 & 0.05 & 0.95 \\
\hline
\end{tabular}

According to the weight ratio of the three major indicators of equipment status, management system, and human operation (4:3:3), the probability that the score is within $(-\infty, 0)$ is 0 , The probability that the score is in the range of $[0,0.2)$ is 0 , the probability that the score is in the range of $[0.2,0.4)$ is 0.085 , the probability that the score is in the range of $[0.4,0.6)$ is 0.01 , and the score is in the range of $[0.6,0.8)$ is 0.03 , the score is 0.20 in the range of $[0.8,1)$.

According to the principle of maximum affiliation, the expert's scoring conclusion is between $[0.8,1)$, $\mathrm{V}=0.887$, indicating that the crane has a higher safety index and a higher overall safety.

\section{Conclusion}

As an indispensable lifting equipment for the development of modern industry, crane is of great significance to the development of modern industry. However, as a large equipment, there are hidden dangers in the process of use, and these risks often induce large accidents. In this paper, the risk assessment method of cranes is studied, and the convenience and feasibility of fuzzy safety evaluation method are analyzed to provide more experience for the further research and development of safety assessment system for small and medium-sized cranes in the future. Combined with the specific situation of crane risk management in related enterprises, the risk of crane is analyzed by using fuzzy safety evaluation method, and the fuzzy safety evaluation method is directly applied to the risk assessment of portal crane.

\section{Acknowledgements}

I would like to express my sincere thanks to Shanghai Pudong New Area Special Equipment Inspection Institute. With the help of my colleagues, I completed this paper.

\section{References}

1. Yao Biquan, Qiao Yunlong, et al. (2016) Analysis of safety accident tree of cable crane. Modern Business Industry, 37 (28): 195-196.

2. Xie Lining. (2015) Risk assessment and countermeasures for tower crane collapse accident. Xi'an University of Science and Technology, Xi'an.

3. Wang Xinhua, Chen Guohua and Liu Shuang, et al. (2014) Causes and countermeasures of safety accidents of large tower cranes. Lifting and Transportation Machinery, (02): 1-7.

4. Pan Liang, Zhang Zuoping. (2013) Analysis on safety assessment of tower crane. Building Safety, 28 (08): 56-59.

5. Liu Jingzhi, Yin Chenbo, et al. (2014) Comprehensive evaluation of safety condition of gantry crane based on fuzzy theory. Mechanical Manufacturing and Automation. 